\title{
Inter-laboratory Test on Thermophysical Properties of the ITER Grade Heat Sink Material
}

\section{Copper-Chromium-Zirconium}

\author{
G. Pintsuk ${ }^{1}$, J. Blumm², W. Hohenauer ${ }^{3}$, R.C. Hula ${ }^{4}$, T. Koppitz ${ }^{1}$, S. Lindig ${ }^{5}$, D. Pitzer ${ }^{1}$, M.

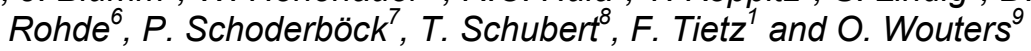 \\ 1 Forschungszentrum Jülich GmbH, EURATOM Association, D-52425 Jülich, Germany; \\ 2 NETZSCH Gerätebau GmbH, D-95100 Selb, Germany; \\ ${ }^{3}$ ARC Seibersdorf research, A-2444 Seibersdorf, Austria; \\ 4 Vienna University of Technology, Getreidemarkt 9/164-CT, A 1060 Vienna, Austria; \\ ${ }_{5}^{5}$ MPI für Plasmaphysik, EURATOM Association, Boltzmannstr.2, D-85748 Garching, Germany; \\ $\underline{6}$ Forschungszentrum Karlsruhe $\mathrm{GmbH}$, Institute for Materials Research I, D-76344 Eggenstein, \\ Germany ; \\ 7 ISPA, Plansee SE, A-6600-Reutte, Austria; \\ $\stackrel{8}{8}$ Fraunhofer-Institute for Manufacturing and Advanced Materials, Winterbergstr. 28, D-01277 \\ Dresden, Germany; \\ 9 NRG Petten, P.O. Box 25, 1755, ZG Petten, The Netherlands
}

Abstract

Copper-chromium-zirconium ( $\mathrm{CuCrZr}$ ) is a commercially available, precipitationstrengthened alloy. The combination of its good thermal conductivity and mechanical strength at low and moderate temperatures made it of interest for use as heat sink material in high heat flux components in actual and future fusion facilities. Its drawback is the microstructural modification and thereby particularly the loss of mechanical strength at temperatures above $500{ }^{\circ} \mathrm{C}$. This limits allowable operational temperatures and also limits the temperature range in which cyclic and reproducible measurements of thermophysical properties can be performed. These difficulties and the international significance of the material makes it an excellent study object for an interlaboratory test of several independent European thermophysical laboratories in which the quality and comparability of thermophysical measurements were determined. The main outcome of this study is that the different laboratory data are in good agreement providing maximum deviations of $\sim 5 \%$ for dilatometry, $2 \%$ for DSC measurements and up to $10 \%$ for thermal diffusivity measurements. In addition to the determined high reproducibility within the particular thermo-physical laboratories, it was found that the average thermal conductivity of CuCrZr produced in a certain compositional range is identical and within a small scatter band.

Keywords: laser flash, dilatometry, calorimetry, ITER, CuCrZr

${ }^{*}$ Corresponding author

e-mail: g.pintsuk@fz-juelich.de,

$$
\begin{aligned}
& \text { Tel.: +49-(0)2461-616300 } \\
& \text { Fax: +49-(0)2461-613699 }
\end{aligned}
$$




\section{Introduction}

Copper-chromium-zirconium is a commercially available, precipitation-strengthened alloy which can be found under several names such as Cu-Cr-Zr (Zollern/Laucherthal), C18150 (Ampco Metals, Inc.), Elbrodur® (KME-AG), Matthey 328 (Johnson Matthey Metals), and YZC (Yamaha Co, Ltd.) [1]. The combination of its good thermal conductivity and mechanical strength at low and moderate temperatures made it of interest for the use as heat sink material in high heat flux components in actual and future fusion facilities, e.g. ITER (International Thermonuclear Experimental Reactor; also Latin for "the way") [2,3], for which a fraction of 0.6 to 0.8 mass $\%$ chromium and 0.07 to 0.15 mass $\%$ zirconium in addition to $\mathrm{Cu}$ is recommended. Its drawbacks are the microstructural modification and thereby particularly the loss of mechanical strength at temperatures above $500{ }^{\circ} \mathrm{C}$ [4] and the limited resistance to neutron irradiation [5], which lead to a limited operational temperature and obligatory thermal treatments during production and component manufacturing [6-8].

This limit in operational temperature determines also a limit for cyclic and reproducible measurement of thermophysical properties of the material, e.g. the coefficient of thermal expansion and thermal diffusivity. The international interest and the significance of the material makes it an excellent study object for an interlaboratory test in which the quality and comparability of thermophysical measurements is determined. In this particular case the participants of the study are eight laboratories involved in ExtreMat, a European FP6 IP-project, and the company Netzsch as an external reference laboratory.

This paper focuses on the consistencies and discrepancies of the measured thermal diffusivities, the specific heat, and the thermal expansion to determine confidence ranges for the particular material properties always with regard to the respective measurement uncertainties given by each laboratory. Furthermore, the reliability of thermo-physical measurements throughout the whole ExtreMat project was aimed to be enhanced. This is a pre-requisite for high standard material development, especially when dealing with special high performance needs for thermal conductance and expansion. 


\section{Experimental}

\subsection{Material}

The CuCrZr material for this study was taken from a bar material $\left(35 \times 35 \times 1000 \mathrm{~mm}^{3}\right)$ produced by the company Zollern/Laucherthal. The composition is Cu-0.8Cr-0.08Zr (in mass\%) with low hardness compared to other $\mathrm{CuCrZr}$ grades [7]. Its production process consists of a solution annealing at $970{ }^{\circ} \mathrm{C}$ for 20 minutes followed by water quenching and aging at $475{ }^{\circ} \mathrm{C}$ for $2 \mathrm{~h}$.

Due to the powder metallurgical production process and the related material densification and deformation of the investigated material by forging, inherent material inhomogeneities and anisotropies have to be taken into account to avoid subsequent scatter of measurement results due to varying material orientations. The determined microstructure shows a texture along the z-axis of the bar that clearly indicated by the deformation of the $\mathrm{Cr}$ particles of about $1 \mu \mathrm{m}$ to $30 \mu \mathrm{m}$ in size in the elongated direction (see Fig. 1). The very low $\mathrm{Zr}$ content within the precipitation strengthened alloy is generally attached to the $\mathrm{Cr}$ particles.

The thermal conductivity of this particular material grade varies, according to the literature, between $\sim 300 \mathrm{~W} \cdot \mathrm{m}^{-1} \cdot \mathrm{K}^{-1}[1]$ and $335 \mathrm{~W} \cdot \mathrm{m}^{-1} \cdot \mathrm{K}^{-1}$ at room temperature (RT) (see Fig. 2). The ITER recommended temperature-dependent thermal conductivity for $\mathrm{CuCrZr}$ is rather constant at $350 \mathrm{~W} \cdot \mathrm{m}^{-1} \cdot \mathrm{K}^{-1}$ to $360 \mathrm{~W} \cdot \mathrm{m}^{-1} \cdot \mathrm{K}^{-1}$ between $\mathrm{RT}$ and $500{ }^{\circ} \mathrm{C}$ However, these values were determined by combining several measurement results on different material grades showing a rather large scatter band and indicating a high demand on the measurement quality. This high demand on the measurement technology, the usage of the investigated material at the Forschungszentrum Jülich for the manufacturing of high heat flux components, and the mentioned large discrepancy of the literature data and the ITER recommendation made this material grade an ideal choice for the performed interlaboratory comparison.

\subsection{Thermo-Physical Characterization}

The main aim of the thermophysical characterization was to determine the temperaturedependent thermal conductivity of the material in the range from RT to $500{ }^{\circ} \mathrm{C}$. For this purpose, the coefficient of thermal expansion influencing the material density $\rho$, the specific heat $c_{p}$, and 
the thermal diffusivity a were measured to subsequently calculate the thermal conductivity $\lambda$ via the formula,

$$
\lambda(T)=a(T) \rho(T) c_{P}(T)
$$

The material orientation of the investigated specimens was chosen to be parallel to the material's deformation direction, and their geometries were adjusted to the particular needs of the respective measurement facilities in the different laboratories (see Table 1). A defined parameter set was provided together with the specimens determining the respective surface treatment, temperature range, atmospheric condition, data acquisition, and repetition rate for the particular measurement procedures: dilatometry, calorimetry (DSC), and laser-flash measurement (LFA) (see Table 2).

The measurement of the thermal expansion was in all cases performed by push-rod dilatometers calibrated to particular reference dimensions (cf. Table 1). The measured $\mathrm{d} / / \mathrm{I}_{0}$ curves supplied by the laboratories were then used to determine the technical coefficient of thermal expansion (CTE) with the reference temperature $\mathrm{T}_{0}=20^{\circ} \mathrm{C}$.

Heat capacities were, on one hand, measured by differential scanning calorimetry. In this method, a small sample with a precisely defined mass is loaded in a controlled heating cycle, and its temperature response is compared to those of a reference sample. The heat flux to and from the sample is a measure of several thermophysical parameters (transition enthalpies, transition temperatures, heat capacities). On the other hand specific heat values were determined by the laser-flash apparatus on $3 \mathrm{~mm}$ and $5 \mathrm{~mm}$ thick specimens in parallel to the measurement of the thermal diffusivity. This method was performed to qualify and quantify possible differences between the two different methods.

The thermal diffusivity was measured by different laser-flash apparatus (LFA), i.e., large scale laser flash facilities as well as micro- and nano-flash devices. In this method, a small discshaped sample is irradiated by a short laser pulse, and the resulting temperature increase on the back side of the sample is measured. From the slope of the temperature versus time curve, thermal diffusivities can be calculated. The evaluation model was the same, i.e., Cowan + pulse length correction [10]. 
For a statistical approach and determination of the confidence intervals, the measurement uncertainties were determined for each method. Furthermore, depending on the stability of the particular method and the material, the results of the cyclic measurements were averaged individually for each partner and the standard deviation was determined. Finally, an averaging across all participating laboratories was made for the three investigated material properties.

\section{Results and Discussion}

\subsection{Push-Rod Dilatometry}

The averages of the provided $\mathrm{d} / / I_{0}$ curves ( $\leq 4$ measurement cycles) are plotted for each partner in Fig. 3a. They show a very good correlation, identical slopes and, with the exception of the Plansee laboratory stating a standard deviation $\leq 3 \%$ for the three investigated specimens, a standard deviation $\leq 1 \%$. This low scatter indicates high reproducibility in a particular measurement device and a high stability of the material with regard to thermal expansion. Based on these curves, the individual CTE values were calculated and are plotted in Fig. 3b together with their average and standard deviations that were reliably determined between 100 ${ }^{\circ} \mathrm{C}$ and $450{ }^{\circ} \mathrm{C}$

The majority of the laboratories provided data within the standard deviation of $\sim 3 \%$ in average. Only the results of two laboratories are located outside this range representing the lower threshold (TU-Vienna) and the upper threshold (Netzsch) of the measured CTE data by an offset of $\pm 5 \%$ in comparison to the average. Since there is no reason to exclude either result, both data sets were taken into account and due to its symmetric spread around the average, they balance each other.

Besides the measurements within the specified temperature range from $\mathrm{RT}$ to $500{ }^{\circ} \mathrm{C}$, measurements were also performed by ARCS starting from $-180{ }^{\circ} \mathrm{C}$ which gives a higher reliability of the RT value and which was determined to be $16.6 \times 10^{-6} \mathrm{~K}^{-1}$. Furthermore, investigations in a high temperature range up to $900^{\circ} \mathrm{C}$ (FZJ-ZAT and FZJ-IEF1) showed the independence of the CTE on the above mentioned problem of material aging.

Based on the CTE measurements, the density, as one essential component for the calculation of the thermal conductivity, was determined taking the temperature-dependent 
volumetric expansion of the material into account and leading to a decrease of density as a function of temperature (see Fig. 4)

\subsection{Differential Scanning Calorimetry (DSC)}

The specific-heat measurements performed by DSC show, similar to dilatometry, a low standard deviation $\leq 2.5 \%$ for each individual laboratory independent of the applied thermal cycles. The particular results and their averages, which are reliably determined in the range from $50{ }^{\circ} \mathrm{C}$ to $500{ }^{\circ} \mathrm{C}$, are plotted in Fig. 5. The determined standard deviation for the average value varies from $\sim 1 \%$ at temperatures $\leq 300{ }^{\circ} \mathrm{C}$ and increases to $\sim 2 \%$ at temperatures $>300$ ${ }^{\circ} \mathrm{C}$. This behavior is related to different slopes found for Netzsch and IPP-Garching on the one hand and ARCS and FZJ on the other hand at temperatures $>300{ }^{\circ} \mathrm{C}$. Furthermore the standard deviation is significantly lower than the given uncertainties of $3 \%$ (Netzsch) and $5 \%$ (all others).

In contrast to the measurements by DSC, the measurements performed at Plansee on 5 $\mathrm{mm}$ thick LFA specimens show a strong dependence of the specific heat on the measurement cycle with a stabilization after the sixth cycle (see Fig. $6 a$ ) at values about $2 \%$ to $4 \%$ lower than the average determined by DSC. The measurement data on the $3 \mathrm{~mm}$ specimens instead are in very good agreement within the standard deviation of the DSC measurement (see Fig. 6b), providing a standard deviation of $\sim 1.5 \%$. This would imply a lower measurement effort as well as higher reliability and consistency of LFA-determined specific heat values with DSC data using thinner specimens. The deeper investigation of this effect was not within the scope of this work.

\subsection{Laser Flash Apparatus (LFA)}

In comparison to the measurement of CTE and specific heat, the determination of the thermal diffusivity by LFA methods is subject to a stronger diversification of used facilities and varying "philosophies" of the particular operators. This includes, among others, the spread of used laser power varying from $8.5 \mathrm{~V}$ to $1750 \mathrm{~V}$. Furthermore, the used sample dimension was not optimal in some cases (cf. Table 1). The recommended diameter to thickness ratio for most materials is between 12.6 to 2 and 12.6 to 3 . In addition, the recommended graphite coating on the front and back surfaces of samples couldn't be used. Due to this large variation of 
experimental conditions, the obtained results and their determined average show a large spread compared to the CTE and specific heat measurements (cf. Fig. 7 for the first and the second cycles). The standard deviation for the first cycle is $\leq 7 \%$ whereas it is lower for the second cycle. This is due to a missing second measurement from NRG, providing data at the lower measurement threshold that would counterbalance the measurement by FZJ which is situated at the upper threshold. The difference between the results of these two laboratories also determines the maximum deviation of thermal diffusivity of $\pm 10 \%$ from the average. This deviation is rather large and cannot be explained by the given measurement uncertainties of 3 $\%$ to $5 \%$.

Despite the strong variation, a similar decreasing slope is observed for all measurement curves (see Fig. 7), which is typical for pure metals and metal alloys. Furthermore, it has to be mentioned, that only the values on the $3 \mathrm{~mm}$ thick specimens, obtained by the Plansee laboratory, were taken into account, because the $5 \mathrm{~mm}$ specimens showed also here a strong cyclic-dependent behavior as was observed for the specific heat.

For an extended comparison the results of the interlaboratory investigation were also in contradiction to the outcome of a second study on the same material within the German "Arbeitskreis Thermophysik" (AK) (see Fig. 8). Therein the material was subject only to LFA measurements performed in nine laboratories of which three already took part in the ExtreMat related campaign. Focusing on the results of these three labs the measured data decrease by up to $5 \%$ for the second campaign which is consistent with the overall tendency (see Fig. 8). Nevertheless, the error bars are widely overlapping with a standard deviation for the AK study of $\leq 4 \%$.

\subsection{Thermal Conductivity}

The calculation of the thermal conductivity from the density, specific heat, and thermal diffusivity was done by using the equation shown in section 2 . Since in the AK only thermal diffusivities were measured, the thermal conductivity was calculated using the herein determined average density and specific heat values. The comparison between the two studies on $\mathrm{CuCrZr}$ shows a difference of $\sim 7 \%$ which becomes larger at higher temperatures (see Fig. 9a). The comparison of both data sets with the recommended material data for ITER already plotted in Fig. 2 shows that there is a very good agreement and especially the results of the 
herein described campaign are very close to this recommendation. Furthermore, these results are in contradiction to the available literature value on this particular material grade (cf. Fig. 2) and they indicate that the thermal conductivity of $\mathrm{CuCrZr}$ is in the range for the ITER application, independent of the material grade.

Besides this promising result, it has to be taken into account that the determination of the thermal conductivity by a single laboratory can lead to a misleading result. This is outlined by Fig. 9b, which shows the calculated thermal conductivity for those five laboratories that have measured both specific heat and thermal diffusivity. Four of them have also measured their own CTE and for IPP-Garching the average CTE value determined herein was used for the evaluation of the thermal conductivity. However, even a change of the CTE of $10 \%$ has an effect on the final result that is $\ll<1 \%$ and this is negligible concerning a $\Delta \lambda_{\max : \min }$ of $\sim 10 \%$ as shown in Fig. 9b. It is interesting, that there is no real spread of the evaluated data as expected from the variations observed by the thermal diffusivity, specific heat and thermal expansion measurements. Three laboratories are measuring about the same values, whereas the results of the other two labs are just subject to a parallel shift by a certain $\Delta \lambda$ of about $30 \mathrm{~W} \cdot \mathrm{m}^{-1} \cdot \mathrm{K}^{-1}$. The reason for the occurrence of these two levels instead of a random distribution is not yet understood.

\section{Conclusion}

The thermal conductivity of $\mathrm{CuCrZr}$ was determined by measurement of thermal expansion, specific heat, and thermal diffusivity. Within these measurements the different laboratory data are in good agreement providing maximum deviations of $\sim 5 \%$ for the dilatometry, $\sim 2 \%$ for the DSC measurements and up to $10 \%$ for the thermal-diffusivity measurements. Important outcomes of this study are the a high reproducibility within the particular thermophysical laboratories and good comparability of the determined data. Furthermore, the thermal conductivity of CuCrZr produced by Zollern is close to the ITER recommendation and therefore significantly higher than reported ealier. This also indicates that the average thermal conductivity of $\mathrm{CuCrZr}$ produced in a certain compositional range is identical and within a small scatter band, 


\section{Acknowledgment}

This work has been performed within the framework of the Integrated European Project „ExtreMat" (Contract NMP-CT-2004-500253) with financial support by the European Community. It only reflects the view of the authors, and the European Community is not liable for any use of the information contained therein.

\section{References}

1. ITER Material Properties Handbook, ITER Document No. G 74 MA 9 00-11-10 W 0.1 (2001)

2. V. Barabash, The ITER International Team, A. Peacock, S. Fabritsiev, G. Kalinin, S. Zinkle, A. Rowcliffe, J.-W. Rensman, A.A. Tavassoli, P. Marmy, P.J. Karditsas, F. Gillemot, M. Akiba, J. Nucl. Mater. 367 - 370, 21 (2007)

3. G. Kalinin, V. Barabash, A. Cardella, J. Dietz, K. loki, R. Matera, R.T. Santoro, R. Tivey, The ITER Home Teams, J. Nucl. Mater. 283 - 287, 10 (2000)

4. A.A.F. Tavassoli, J. Nucl. Mater. $258-263,85$ (1998)

5. S.A. Fabritisiev, S.J. Zinkle, B.N. Singh, J. Nucl. Mater. 233 - 237, 127 (1996)

6. A. Durocher, D. Ayrault, Ch. Chagnot, M. Lipa, W. Saikaly, J. Nucl. Mater. $367-370$, $1208(2007)$

7. M. Lipa, A. Durocher, R. Tivey, Th. Huber, B. Schedler, J. Weigert, Fus. Eng. Des. 75 $79,469(2005)$

8. X. Wu, X. Pan, B.N. Singh, M. Li, J.F. Stubbins, J. Nucl. Mater. 45. $367-370,984$ (2007)

9. Product brochure, Zollern GmbH \& Co. KG, www.zollern.de (2010)

10. R.D. Cowan, J. Appl. Phys. 34, 926 (1963) 


\begin{tabular}{l|l|l|l} 
Laboratory & Dilatometry & Calorimetry & Laser Flash \\
\hline Netzsch & $\varnothing=6 \mathrm{~mm}, \mathrm{I}=25 \mathrm{~mm}$ & $\varnothing=5 \mathrm{~mm}, \mathrm{~d}=1 \mathrm{~mm}$ & $\varnothing=12.7 \mathrm{~mm}, \mathrm{~d}=3 \mathrm{~mm}$ \\
\hline FZJ & $\begin{array}{l}4 \times 4 \times 25 \mathrm{~mm}^{3}(\mathrm{IEF}-1) \\
\varnothing=6 \mathrm{~mm}, \mathrm{I}=25 \mathrm{~mm}(\mathrm{ZAT})\end{array}$ & $\varnothing=5 \mathrm{~mm}, \mathrm{~d}=1 \mathrm{~mm}$ & $\varnothing=10 \mathrm{~mm}, \mathrm{~d}=3 \mathrm{~mm}$ \\
\hline ARCS & $4 \times 4 \times 12 \mathrm{~mm}^{3}$ & $\varnothing=5 \mathrm{~mm}, \mathrm{~d}=1 \mathrm{~mm}$ & $\varnothing=10 \mathrm{~mm}, \mathrm{~d}=3 \mathrm{~mm}$ \\
\hline IPP-Garching & $---5 \mathrm{~mm}, \mathrm{~d}=1 \mathrm{~mm}$ & $\varnothing=12.7 \mathrm{~mm}, \mathrm{~d}=2 \mathrm{~mm}$ \\
\hline IFAM & $4 \times 4 \times 15 \mathrm{~mm}^{3}$ & $\varnothing=5 \mathrm{~mm}$ \\
\hline TU-Vienna & $4 \times 4 \times 10 \mathrm{~mm}^{3}$ & --- & $\varnothing=12.7 \mathrm{~mm}, \mathrm{~d}=3 \mathrm{~mm}$ \\
\hline Plansee & $5 \times 5 \times 20 \mathrm{~mm}^{3}$ & --- & $\varnothing=6 \mathrm{~mm}, \mathrm{~d}=3 \mathrm{~mm}$ \\
\hline NRG & $\varnothing=8 \mathrm{~mm}, \mathrm{~d}=6 \mathrm{~mm}^{2}$ & meas. by laser flash & $\varnothing=12.6 \mathrm{~mm}, \mathrm{~d}=3 \mathrm{~mm}$ \\
\hline
\end{tabular}

Table 1 Specimen geometries for the three measurement techniques and the different laboratories 


\section{Measurement methods}

\begin{tabular}{|c|c|c|}
\hline \multirow{6}{*}{$\begin{array}{l}\text { Laser flash (LFA) } \\
\text { Thermal diffusivity }\end{array}$} & Number of samples: & 3 \\
\hline & Data: & thermal diffusivity in $50^{\circ} \mathrm{C}$ steps \\
\hline & Sample treatment: & Sandblasted (no coating) \\
\hline & Temperature range: & $\begin{array}{l}\text { RT }-\mathbf{5 0 0}{ }^{\circ} \mathbf{C}: \\
\text { RT, } 100^{\circ} \mathrm{C} \text { then steps of } 50^{\circ} \mathrm{C}\end{array}$ \\
\hline & Atmosphere & inert atmosphere \\
\hline & Repetition & at least 2 cycles / sample \\
\hline \multirow{6}{*}{$\begin{array}{l}\text { Dilatometer } \\
\text { Thermal expansion }\end{array}$} & Number of samples: & 3 \\
\hline & Data: & $\begin{array}{l}\text { d } / I I_{0} \text {; only heating curves; ASCII data } \\
\text { in } 5^{\circ} \mathrm{C} \text { steps }\end{array}$ \\
\hline & Temperature range: & $\begin{array}{l}\mathbf{R T}-\mathbf{5 0 0}{ }^{\circ} \mathbf{C} \\
\text { start from negative temperature } \\
\text { possible - do not exceed } 510^{\circ} \mathrm{C}\end{array}$ \\
\hline & Heating rate: & $\max .5^{\circ} \mathrm{C} / \min$ \\
\hline & Atmosphere & inert atmosphere (He recommended) \\
\hline & Repetition: & at least 2 cycles / sample \\
\hline \multirow{5}{*}{$\begin{array}{l}\text { Calorimetry } \\
\text { Specific heat }\end{array}$} & Number of samples: & 2 \\
\hline & Data & only heating curves; data in $5^{\circ} \mathrm{C}$ steps \\
\hline & Temperature range: & $\begin{array}{l}\text { RT }-500{ }^{\circ} \mathbf{C} \text {, (heating rate depending } \\
\text { on sensor) } \\
\text { start from negative temperature } \\
\text { possible - do not exceed } 510^{\circ} \mathrm{C}\end{array}$ \\
\hline & Atmosphere & inert atmosphere \\
\hline & Repetition: & at least 2 cycles / sample \\
\hline
\end{tabular}

Table 2 Measurement parameter set for the determination of the three thermo-physical material properties 


\section{Figure captions}

Fig. 1 Microstructure of $\mathrm{CuCrZr}$ with deformed Cr-precipitations along the longitudinal axis of the CuCrZr bar

Fig. 2 Thermal conductivity for CuCrZr according to the ITER recommendation (equation valid for $\mathrm{T} \leq$ $500^{\circ} \mathrm{C}$ ) and the literature values $[1,9]$ for the material provided by Zollern

Fig. 3 Results from push-rod dilatometry versus temperature: (a) relative elongation and (b) coefficient of thermal expansion with average and standard deviation between $100{ }^{\circ} \mathrm{C}$ and $500{ }^{\circ} \mathrm{C}$

Fig. 4 Density as a function of temperature; measurement at RT, calculated for $T>R T$ with data taken from Fig. 3

Fig. 5 Specific heat measured by DSC; average and standard deviations between $50^{\circ} \mathrm{C}$ and $500{ }^{\circ} \mathrm{C}$

Fig. 6 Specific heat measured by laser-flash apparatus in comparison to the values obtained by DSC;

(a) first and seventh cycle on $5 \mathrm{~mm}$ thick specimens and (b) average values for $3 \mathrm{~mm}$ and saturation value for $5 \mathrm{~mm}$ thick specimens

Fig. 7 Thermal diffusivity measured by LFA, average and standard deviations between RT and $500^{\circ} \mathrm{C}$; (a) first cycle and (b) second cycle without data from NRG and hence slightly higher average

Fig. 8 Thermal diffusivity measured by LFA: comparison of average values of two different measurement campaigns (IC: first and second cycles)

Fig. 9 Calculation of thermal conductivity: (a) comparison of IC average, AK average and ITER recommendation between $\mathrm{RT}$ and $500{ }^{\circ} \mathrm{C}$ and (b) comparison of data from five laboratories measuring both specific heat and thermal diffusivity between $100^{\circ} \mathrm{C}$ and $500{ }^{\circ} \mathrm{C}$ 
Deformation / measurement direction

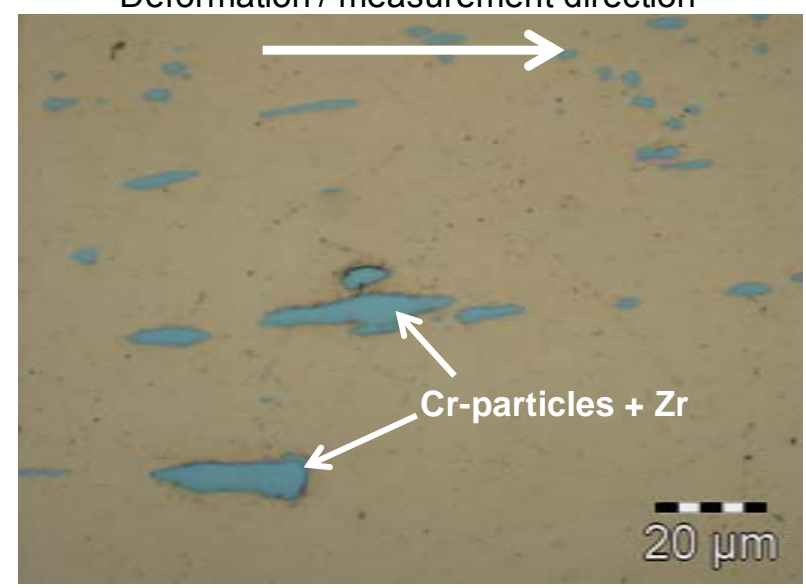

Fig. 1 


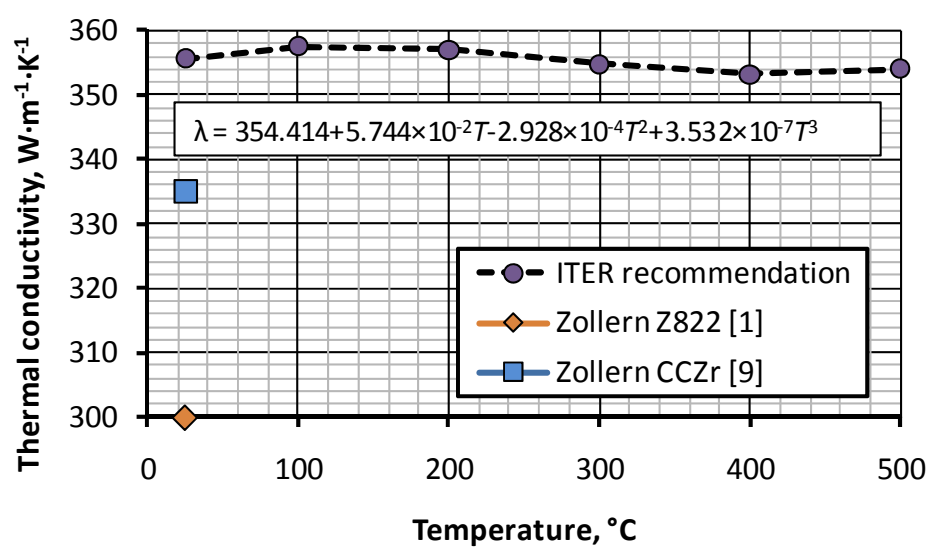

Fig. 2 


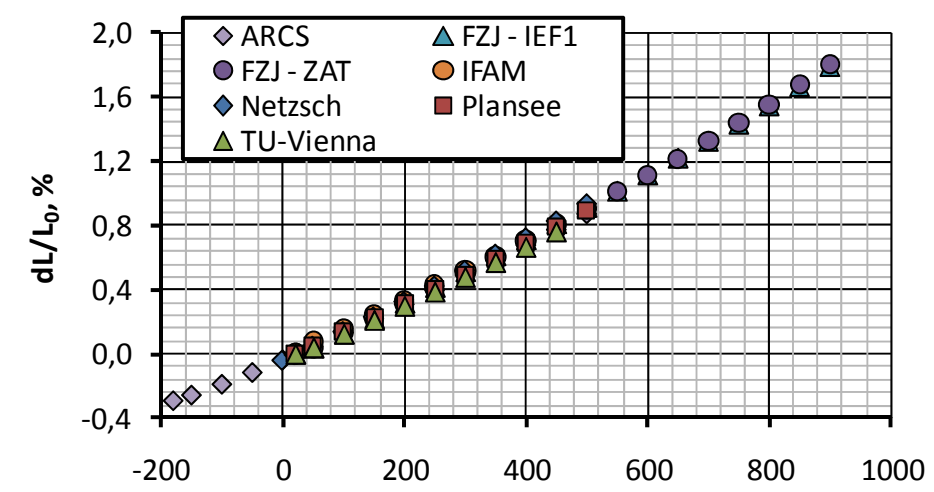

a

Temperature, ${ }^{\circ} \mathrm{C}$

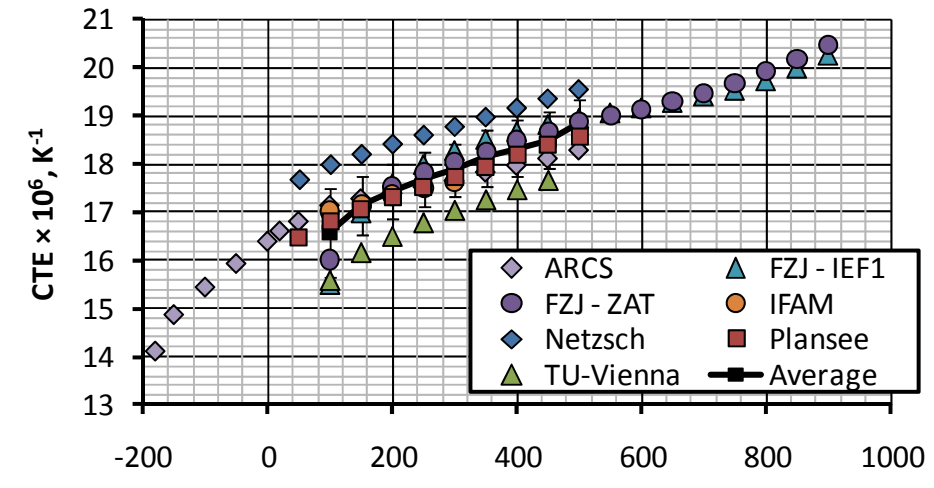

b $\quad$ Temperature, ${ }^{\circ} \mathrm{C}$

Fig. 3 


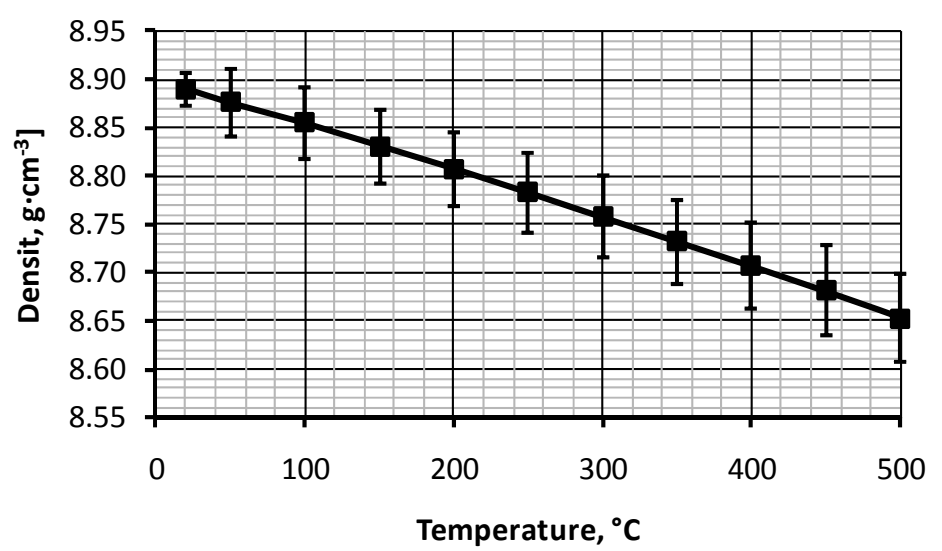

Fig. 4 


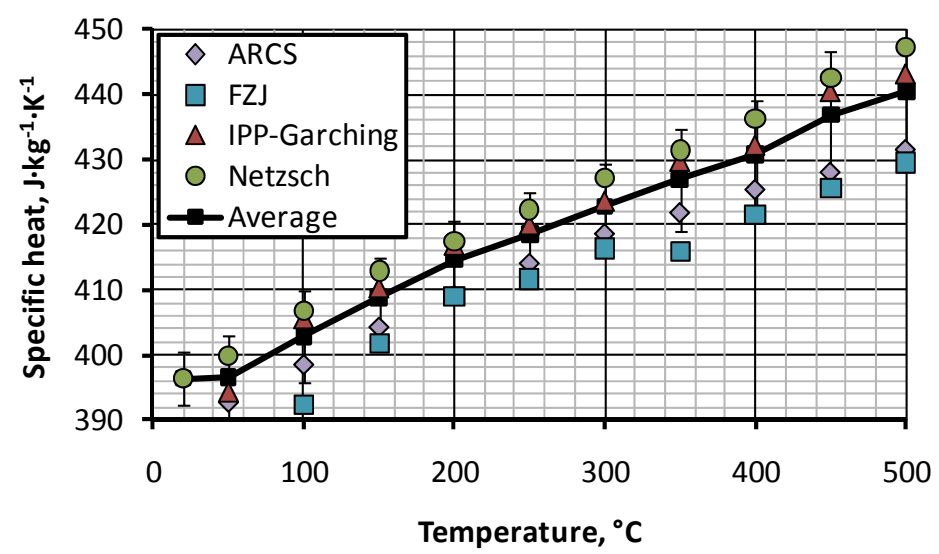

Fig. 5 


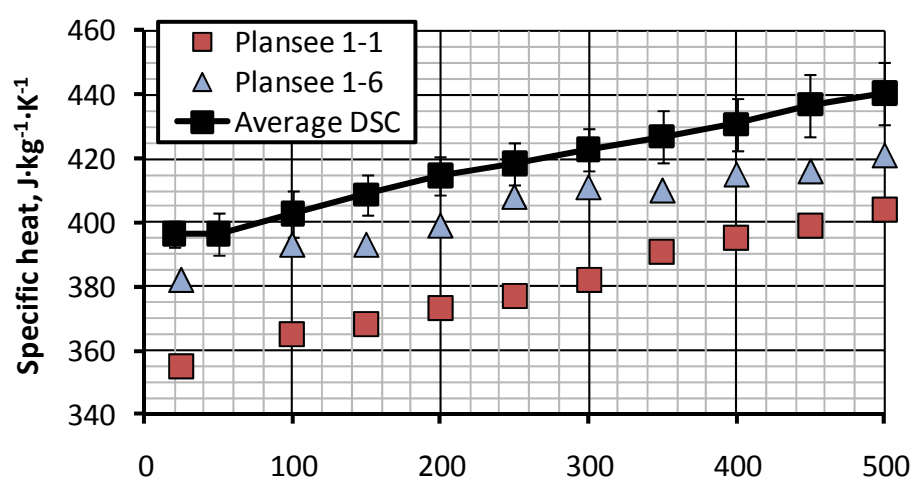

a

Temperature, ${ }^{\circ} \mathrm{C}$

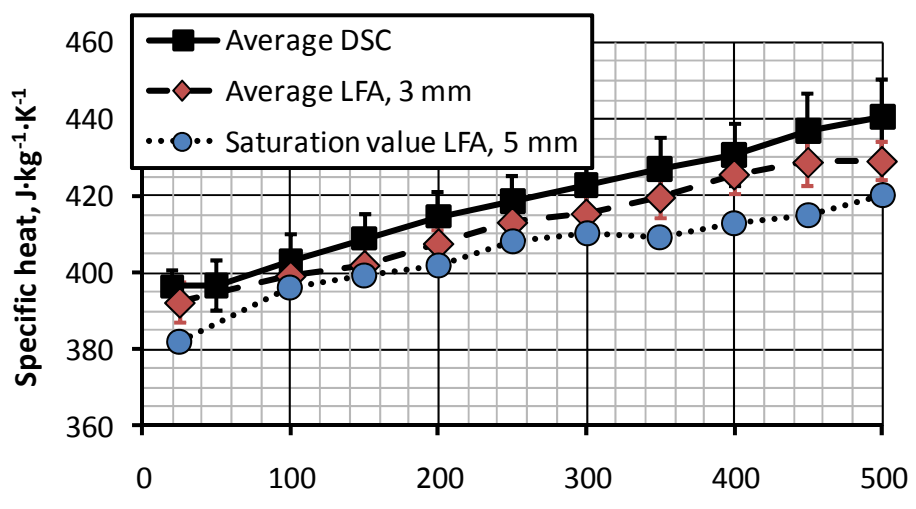

Temperature, ${ }^{\circ} \mathrm{C}$

Fig. 6 


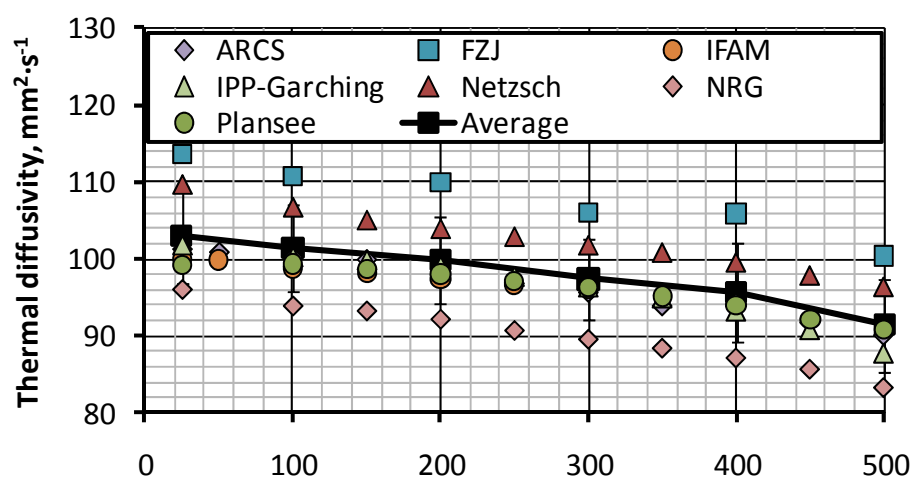

a

Temperature, ${ }^{\circ} \mathrm{C}$

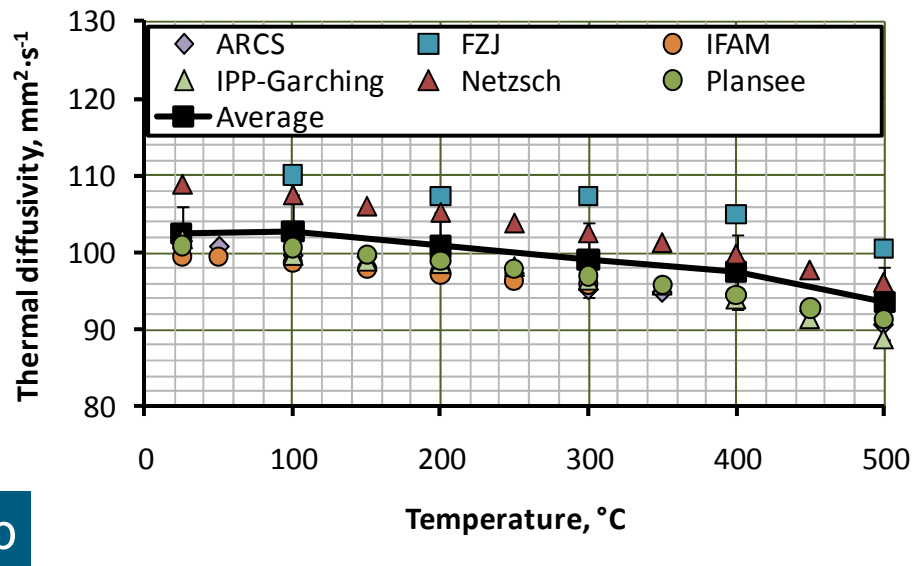

Fig. 7 


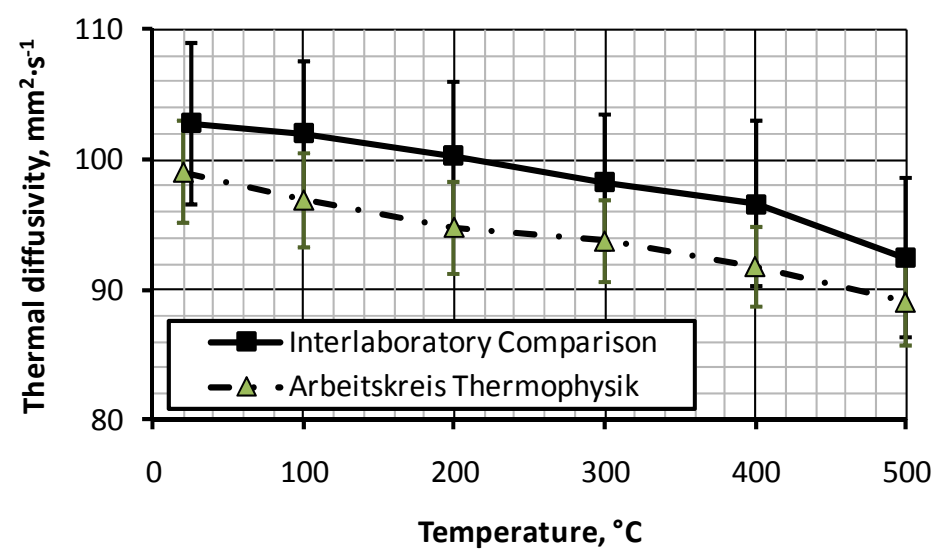

Fig. 8 


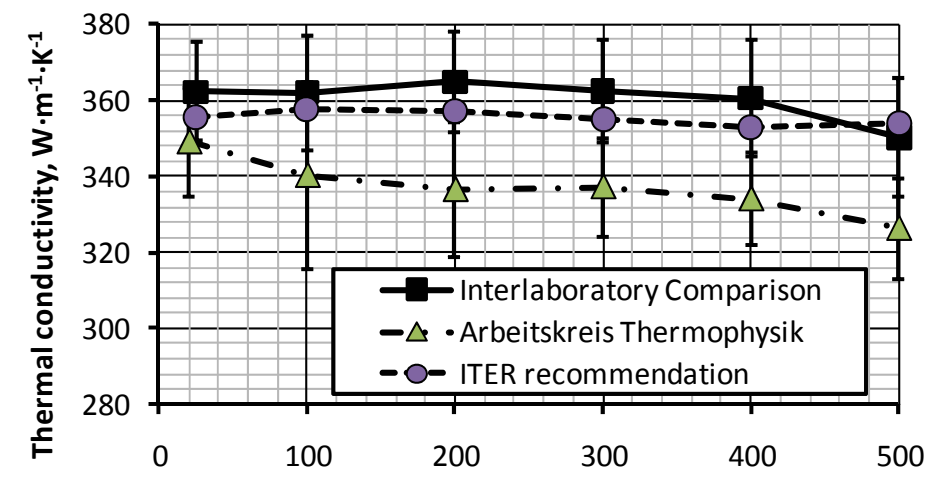

a

Temperature, ${ }^{\circ} \mathrm{C}$

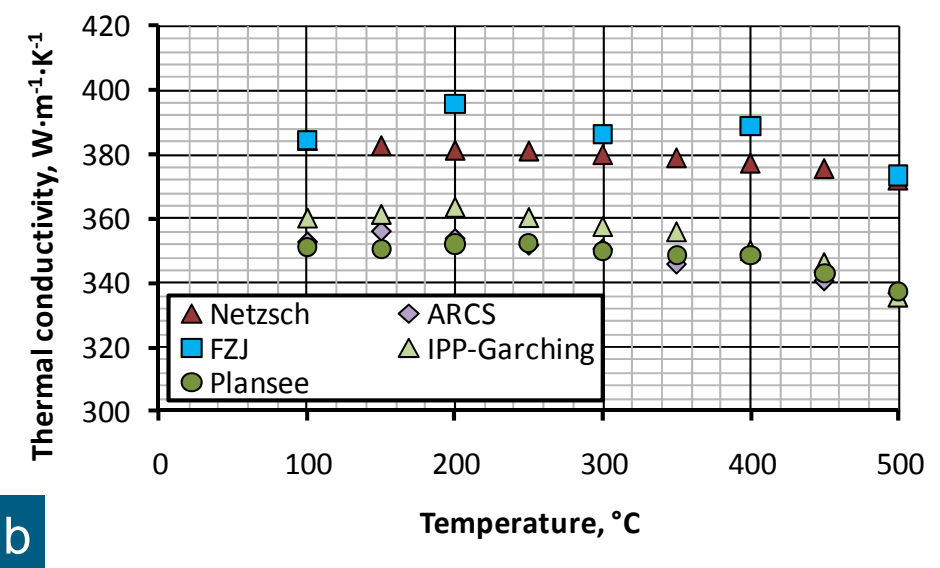

Fig. 9 